\title{
吸音材内部における散逸エネルギ一の寄与解析
}

\author{
山本 崇史 ${ }^{* 1}$, 桂 大詞 ${ }^{* 2}$, 久保田 寛 ${ }^{* 2}$
}

\section{Dissipation energy in sound-absorbing poroelastic material}

\author{
Takashi YAMAMOTO*1 $^{*}$, Daiji KATSURA ${ }^{* 2}$ and Hiroshi KUBOTA ${ }^{* 2}$ \\ ${ }^{* 1}$ Department of Mechanical Engineering, Kogakuin University \\ 2665-1 Nakano-machi, Hachioji-shi, Tokyo 192-0015, Japan \\ ${ }^{* 2}$ Mazda Motor Corporation \\ 3-1 Shinchi, Fuchu-cho, Aki-gun, Hiroshima 730-8670, Japan
}

Received: 11 November 2019; Revised: 3 February 2020; Accepted: 7 June 2020

\begin{abstract}
In sound-absorbing poro-elastic media, the energy of incident sound wave is dissipated through the following three mechanisms: the viscous dissipation arising the vicinity of the boundary between the solid and fluid phases due to the viscosity of air, the thermal dissipation, and the viscoelastic dissipation due to the damping property of the material used in the solid phase. Contribution of these three dissipated energies are not clear, although the incident energy is considered to be mainly dissipated by the viscous dissipation. In order to evaluate numerically these three dissipated energy separately in the finite element method, one needs to access element matrices, which is generally not easy in commercial softwares. Thus, in the study presented here, we evaluate the dissipated energies by using the analytical solutions for one-dimensional wave equations assuming that the sound is incident normal to the poro-elastic material. Moreover, we analyze the characteristics of the frequency spectrum of the sound-absorbing coefficient by using the relationship between the viscous dissipation and the particle velocity relative to the velocity of the constructed elastic material.
\end{abstract}

Keywords : Sound absorption, Dissipation, Porous material, Viscosity

1. 緒言

吸音材の代表的な評価指標である吸音率は，入射音波の音響エネルギーに対する吸音材内部で散逸されたエネ ルギーの比として定義されている．しかし，材料内部での散冕エネルギーの計測は難しいことから，反射率を計測 し, 反射率の二乗を 1 より減ずることで吸音率を間接的に求めている. 散逸のメカニズムとして, 空気の粘性に よる散逸, 膨張・圧縮に伴う熱の散逸, 材料の粘弾性特性による散逸が考えられる. 一般的な吸音材の場合, 空 気の粘性による散逸の寄与が大きいとされているが，各散逸エネルギーの定量的な寄与については明確でない点 が多い.

振動問題において，1 周期の間に振動系内部で散逸されるエネルギーは，ヒステリシスループの囲む面積で求め ることができる. 応力とひずみを複素形式で表す場合, 応力とひずみの複素共役の積の実部として求めることがで き, これは, 運動方程式の弱形式において, 許容変分に代えて振動速度の複素共役を用いることでも求めること

No.19-00415 [DOI:10.1299/transjsme.19-00415], J-STAGE Advance Publication date : 17 June, 2020

*1 正員, 工学院大学工学部 機械工学科（产 192-0015 東京都八王子市中野町 2665-1)

*2 マツダ (株) 技術研究所 ( 730 -8670 広島県安芸郡府中町新地 3-1)

E-mail of corresponding author: takashi_yamamoto@cc.kogakuin.ac.jp 
ができる．多孔質吸音材の動的挙動を表現できる Biot のモデル (Biot, 1956a,b; Allard and Atalla, 2009; Atalla et al., 1998) に，同様の考え方を適用し，Sgard (Sgard et al., 2000) ら，および Dazel (Dazel et al., 2007) らは，有限要素法 により各散逸エネルギーを数值的に求めている. また, Yamamoto (Yamamoto et al., 2011) は, 同様に有限要素法 により材料内部における散逸エネルギーの分布を明らかにしている.

しかし，空気の粘性による散冕，膨張・圧縮に伴う熱の散冕，材料の粘弾性特性による散冕の寄与を算出する ためには, 要素マトリックスを用いる必要があり, 汎用ソルバーを用いた計算のポスト処理で散逸エネルギーを求 めることは難しい.

そこで，本研究では，垂直入射吸音率の場合に限定し，1 次元の管内を伝播する音波に対する波動方程式の理論 解を用いて, 解析的に各散逸エネルギーを求める. また, 空気の粘性による散逸エネルギーと, 固体相・流体相 間の相対速度の関係に着目し，エネルギー散逸のメカニズムを明らかにする.

以下， 2 章では，まず，弾性体の場合について，散逸エネルギーがヒステリシスループの囲む面積に等しくなる ことを用いて，散逸エネルギーを算出する方法をまとめておく，そして，3 章では，その方法を応用し，1 次元の 多孔質吸音材内部を伝播寸る音波の解析解を適用して，空気の粘性による散逸エネルギー，膨張・圧縮に伴う熱 の散逸エネルギー，材料の粘弾性特性による散逸エネルギーを解析的に求める. 4 章では，音響管内に設置された 多孔質吸音材に対して適用寸る. 5 章では, 既存の多孔質吸音材の材料特性を用いて, 各散逸エネルギーの寄与の 周波数特性を算出する. また, 空気の粘性による散逸エネルギーと, 固体相・流体相間の相対速度の関係に着目 し，散逸のメカニズムについて検討する．最後に 6 章で，本研究のまとめと今後の課題について述べる.

\section{2. 弾性体内部における散逸エネルギー}

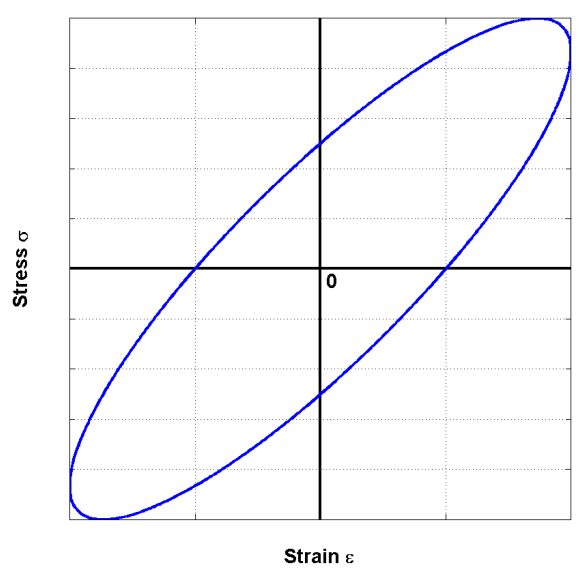

Fig. 1 Stress - strain curve for typical viscoelastic material. Potential energy dissipated in a vibration cycle time is given as the area the curve encloses.

多孔質材内部における散逸エネルギーを考える前にまず，弾性体内部における散逸エネルギーを求める式を示 しておく.ポテンシャルエネルギーの散逸は, 図 1 亿示すように, 応力ひずみ線図が囲む面積で求められること はよく知られている.ここでは, 運動方程式を用いて一般的な式を導出する.

領域 $\Omega^{e}$, 境界 $\Gamma^{e}$ を有する線形弾性体について, 応力を $\bar{\sigma}_{i j}^{e}$, ひずみを $\bar{\varepsilon}_{i j}^{e}$, 質量密度を $\bar{\rho}^{e}$, 変位を $\bar{u}_{i}^{e}$, 速度を $\bar{v}_{i}^{e}$ と し，いずれも実数值の時間 $t$ の関数とすると，運動方程式は次式で書くことができる.

$$
\bar{\rho}^{e} \frac{\partial \bar{v}_{i}^{e}}{\partial t}=\frac{\partial \bar{\sigma}_{i j}^{e}}{\partial x_{j}}
$$

なお, $n_{j}^{e}$ は境界 $\Gamma^{e}$ で定義される領域外向きの法線方向を表す. 両辺に速度 $\bar{v}_{i}^{e}$ をかけて領域で積分し, 発散定理 
を用いた後，ひずみ $\bar{\varepsilon}_{i j}^{e}$ を使うと次式となる.

$$
\int_{\Omega^{e}} \bar{\rho}^{e} \dot{\bar{v}}_{i}^{e} v_{i} d \Omega+\int_{\Omega^{e}} \bar{\sigma}_{i j}^{e} \dot{\bar{\varepsilon}}_{i j}^{e} d \Omega=\int_{\Gamma^{e}}\left(\bar{\sigma}_{i j}^{e} n_{j}^{e} \dot{\bar{u}}_{i}^{e}\right) d \Gamma
$$

次に，式 (1) の線形弾性体の運動方程式を時間で 1 階微分すると以下となる.

$$
\frac{\partial}{\partial t}\left(\bar{\rho}^{e} \frac{\partial \bar{v}_{i}^{e}}{\partial t}\right)=\frac{\partial \dot{\bar{\sigma}}_{i j}^{e}}{\partial x_{j}}
$$

両辺に変位 $\bar{u}_{i}^{e}$ をかけて領域 $\Omega^{e}$ で積分し，発散定理を用い，ひずみ $\bar{\varepsilon}_{i j}^{e}$ を使うと次式となる.

$$
\int_{\Omega^{e}} \frac{\partial\left(\bar{\rho}^{e} \dot{\bar{v}}_{i}^{e}\right)}{\partial t} \bar{u}_{i}^{e} d \Omega+\int_{\Omega^{e}} \dot{\bar{\sigma}}_{i j}^{e} \bar{\varepsilon}_{i j}^{e} d \Omega=\int_{\Gamma^{e}}\left(\dot{\bar{\sigma}}_{i j}^{e} n_{j}^{e} \bar{u}_{i}^{e}\right) d \Gamma
$$

式 (2) から式 (4) を辺々引いて周期 $T$ で積分し, 積分順序の交換は可能であることを考慮すると, 次式のように書 くことができる.

$$
\begin{aligned}
\int_{\Omega^{e}} \int_{0}^{T} \frac{1}{2}\left(\bar{\rho}^{e} \dot{\bar{v}}_{i}^{e} \bar{v}_{i}-\frac{\partial\left(\bar{\rho}^{e} \dot{\bar{v}}_{i}^{e}\right)}{\partial t} \bar{u}_{i}^{e}\right) d t d \Omega+\int_{\Omega^{e}} \int_{0}^{T} \frac{1}{2}\left(\bar{\sigma}_{i j}^{e} \dot{\bar{\varepsilon}}_{i j}^{e}-\dot{\bar{\sigma}}_{i j}^{e} \bar{\varepsilon}_{i j}^{e}\right) d t d \Omega & \\
& =\int_{\Gamma^{e}} \int_{0}^{T} \frac{1}{2}\left(\bar{\sigma}_{i j}^{e} n_{j}^{e} \dot{\bar{u}}_{i}^{e}-\dot{\bar{\sigma}}_{i j}^{e} n_{j}^{e} \bar{u}_{i}^{e}\right) d t d \Gamma
\end{aligned}
$$

ガウスグリーンの定理より, 左辺第一項は運動エネルギーの散逸, 左辺第二項はポテンシャルエネルギーの散逸, 右辺は境界における外部からの入力エネルギーを表しており, 外部から入力されるエネルギーと領域内部で散逸 されるエネルギーが等しいことを示している.

ここで, 応力, ひずみ, 質量密度, 変位, および速度を複素形式で書き複素数の関数で表したものをそれぞれ $\sigma_{i j}^{e}, \varepsilon_{i j}^{e}, \rho^{e}, u_{i}^{e}$,および $v_{i}^{e}$ とし, *で複素共役であることを示すものとすると, 角振動数を $\omega$ として上式は以下のよ うに表すことができる。

$$
\int_{\Omega^{e}} \frac{1}{2} \Re\left(\rho^{e} \dot{v}_{i}^{e} v_{i}^{e *}\right) \frac{2 \pi}{\omega} d \Omega+\int_{\Omega^{e}} \frac{1}{2} \Re\left(\sigma_{i j}^{e} \dot{\varepsilon}_{i j}^{e *}\right) \frac{2 \pi}{\omega} d \Omega=\int_{\Gamma^{e}} \frac{1}{2} \Re\left(\sigma_{i j}^{e} n_{j}^{e} \dot{u}_{i}^{e *}\right) \frac{2 \pi}{\omega} d \Gamma
$$

調和振動を仮定すると，虚数単位を $j$ として次式で書き直すことができる.

$$
\frac{1}{2} \Re\left[\int_{\Omega^{e}}(j \omega)\left(\rho^{e} \omega^{2} u_{i}^{e} u_{i}^{e *}\right) d \Omega+\int_{\Omega^{e}}(-j \omega)\left(\sigma_{i j}^{e} \varepsilon_{i j}^{e *}\right) d \Omega\right]=\frac{1}{2} \Re\left[\int_{\Gamma^{e}} \sigma_{i j}^{e} n_{j}^{e} \dot{u}_{i}^{e *} d \Gamma\right]
$$

ここで, 線形弾性体の運動方程式の弱形式は, 許容される変分を $\delta u_{i}^{e}$ とすると以下のように書くことができる.

$$
\int_{\Omega^{e}}\left(\sigma_{i j}^{e} \delta \varepsilon_{i j}^{e}-\rho^{e} \omega^{2} u_{i}^{e} \delta u_{i}^{e}\right) d \Omega=\int_{\Gamma^{e}} \sigma_{i j}^{e} n_{j}^{e} \delta u_{i}^{e} d \Gamma
$$

ここで, $\delta u_{i}^{e}$ を $-j \omega u_{i}^{e *}$ に置き換え, 両辺の実部をとると次式のように書ける.

$$
\frac{1}{2} \Re\left[(-j \omega) \int_{\Omega^{e}}\left(\sigma_{i j}^{e} \varepsilon_{i j}^{e^{*}}-\rho^{e} \omega^{2} u_{i}^{e} u_{i}^{e *}\right) d \Omega\right]=\frac{1}{2} \Re\left[\int_{\Gamma^{e}} \sigma_{i j}^{e} n_{j}^{e} \dot{u}_{i}^{e *} d \Gamma\right]
$$

これは式(6) に等しいことが分かる，すなわち，運動方程式の弱形式において，変分 $\delta u_{i}^{e}$ を $-j \omega u_{i}^{e *}$ に置き換え， 実部をとることで, 領域内部で散逸されるエネルギーおよび境界において外部から入力されるエネルギーを求め られることが分かる.

\section{3. 多孔質吸音材内部における散逸エネルギー}

\subsection{Biot モデルの運動方程式と構成式}

本研究では, Biot のモデル (Biot, 1956a,b; Allard and Atalla, 2009; Atalla et al., 1998) を用いて多孔質吸音材の動 的挙動を表現する. 多孔質吸音材の固体相の変位を $u_{i}^{s}$, 流体相の音圧を $p^{f}$ とし, 流体相の速度ポテンシャル $\psi^{f}$ を用いて $p^{f}=-j \omega \psi^{f}$ とすると，固体相および流体相の運動方程式は次式で表される.

$$
\frac{\partial \hat{\sigma}_{i j}^{s}}{\partial x_{j}}+\rho \omega^{2} u_{i}^{s}-j \omega \tilde{\gamma} \frac{\partial \psi^{f}}{\partial x_{i}}=0
$$




$$
\frac{\phi^{2}}{\tilde{\rho}_{22}} \frac{\partial^{2} \psi^{f}}{\partial x_{i}^{2}}+\omega^{2} \frac{\phi^{2}}{R} \psi^{f}-j \omega \tilde{\gamma} \frac{\partial u_{i}^{s}}{\partial x_{i}}=0
$$

ここで， $\hat{\sigma}_{i j}^{s}$ は固体相の真空雰囲気での応力で, $\rho=\tilde{\rho}_{11}-\frac{\tilde{\rho}_{12}^{2}}{\tilde{\rho}_{22}}, \quad \tilde{\gamma}=\phi\left(\frac{\tilde{\rho}_{12}}{\tilde{\rho}_{22}}-\frac{Q}{R}\right)$ である.また, $\tilde{\rho}_{11}, \tilde{\rho}_{12}$ および $\tilde{\rho}_{22}$ は，固体相と流体相の境界における粘性減衰を考慮した等価密度でそれぞれ以下のように表わされる.

$$
\begin{aligned}
& \tilde{\rho}_{11}=(1-\phi) \rho^{s}+\left(\alpha_{\infty}-1\right) \phi \rho^{f}-j \frac{\sigma \phi^{2}}{\omega} G_{j}(\omega) \\
& \tilde{\rho}_{12}=-\left(\alpha_{\infty}-1\right) \phi \rho^{f}+j \frac{\sigma \phi^{2}}{\omega} G_{j}(\omega) \\
& \tilde{\rho}_{22}=\phi \rho^{f}+\left(\alpha_{\infty}-1\right) \phi \rho^{f}-j \frac{\sigma \phi^{2}}{\omega} G_{j}(\omega)
\end{aligned}
$$

$\rho^{s}$ おび $\rho^{f}$ はそれぞれ固体相および流体相の質量密度であり， $\phi$ は空孔率,$\alpha_{\infty}$ はトーチュオシティ, $\sigma$ は空気流 れ抵抗である. また, $G_{j}(\omega)$ は $v$ を動粘性係数， $\Lambda$ を粘性代表長さとして次式で表わされる.

$$
G_{j}(\omega)=\left(1+\frac{4 j \omega v}{\Lambda^{2}} \frac{\rho^{f 2} \alpha_{\infty}^{2}}{\sigma^{2} \phi^{2}}\right)^{\frac{1}{2}}
$$

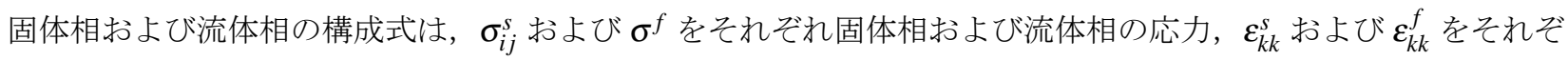
れ固体相および流体相の体積ひずみとして，次式で与えられる.

$$
\begin{aligned}
\sigma_{i j}^{s} & =\hat{\sigma}_{i j}^{s}-\frac{Q}{R} \phi p^{f} \delta_{i j} \\
\sigma^{f} & =-\phi p^{f}=Q \varepsilon_{k k}^{s}+R \varepsilon_{k k}^{f}
\end{aligned}
$$

ここで， $\delta_{i j}$ は Kronecker のデルタ， $Q$ とR は体積弾性率で一般的な多孔質吸音材では次式で近似的に表すことが できる。

$$
Q \approx(1-\phi) K^{f}, R \approx \phi K^{f}
$$

$K^{f}$ は熱の固体相への散逸による減衰を考慮した流体相の等価体積弾性率で, 比熱比 $\gamma^{f}$, 平衡状態の圧力 $P_{0}^{f}$, 温 度拡散率 $v^{\prime}$ を用いて次式で表わされる。

$$
K^{f}=\frac{\gamma^{f} P_{0}^{f}}{\gamma^{f}-\left(\gamma^{f}-1\right)\left[1+\frac{8 v^{\prime}}{j \omega \Lambda^{\prime 2}} H(\omega)\right]^{-1}}, H(\omega)=\left(1+\frac{j \omega \Lambda^{\prime 2}}{16 v^{\prime}}\right)^{\frac{1}{2}}
$$

ここで， $\Lambda^{\prime}$ は温度代表長さである．

\section{$3 \cdot 2$ 多孔質吸音材で散逸されるエネルギー}

固体相および流体相の変分をそれぞれ $\delta u_{i}^{s}, \delta \psi^{f}$ とすると，運動方程式の弱形式はそれぞれ以下のように書く ことができる.

$$
\begin{aligned}
& \int_{\Omega}\left(\frac{\partial \hat{\sigma}_{i j}^{s}}{\partial x_{j}}+\rho \omega^{2} u_{i}^{s}-j \omega \tilde{\gamma} \frac{\partial \psi^{f}}{\partial x_{i}}\right) \delta u_{i}^{s} d \Omega=0 \\
& \int_{\Omega}\left(\frac{\phi^{2}}{\tilde{\rho}_{22}} \frac{\partial^{2} \psi^{f}}{\partial x_{i}^{2}}+\omega^{2} \frac{\phi^{2}}{R} \psi^{f}-j \omega \tilde{\gamma} \frac{\partial u_{i}^{s}}{\partial x_{i}}\right) \delta \psi^{f} d \Omega=0
\end{aligned}
$$

ここで， $\Omega$ は多孔質吸音材が占める領域である．整理すると以下のように書くことができる.

$$
\int_{\Omega}\left[\hat{\sigma}_{i j}^{s} \delta \varepsilon_{i j}^{s}-\rho \omega^{2} u_{i}^{s} \delta u_{i}^{s}+j \omega(\alpha+\tilde{\gamma}) \frac{\partial \psi^{f}}{\partial x_{i}} \delta u_{i}^{s}+j \omega \alpha \psi^{f} \frac{\partial \delta u_{i}^{s}}{\partial x_{i}}\right] d \Omega=\int_{\Gamma} \sigma_{i j}^{p} n_{j} \delta u_{i}^{s} d \Gamma
$$




$$
\int_{\Omega}\left[-\frac{\phi^{2}}{\tilde{\rho}_{22}} \frac{\partial \psi^{f}}{\partial x_{i}} \frac{\partial \delta \psi^{f}}{\partial x_{i}}+\omega^{2} \frac{\phi^{2}}{R} \psi^{f} \delta \psi^{f}+j \omega(\alpha+\tilde{\gamma}) u_{i}^{s} \frac{\partial \delta \psi^{f}}{\partial x_{i}}+j \omega \alpha \frac{\partial u_{i}^{s}}{\partial x_{i}} \delta \psi^{f}\right] d \Omega=\int_{\Gamma}-j \omega \phi\left(u_{n}^{f}-u_{n}^{s}\right) \delta \psi^{f} d \Gamma
$$

ここで，「は多孔質吸音材を囲む境界で，添字記号 $n$ は境界法線方向であることを示しており， $n_{i}$ はその方向成 分である. また, $\sigma_{i j}^{p}=\sigma_{i j}^{s}-\phi p^{f} \delta_{i j}, \alpha=\phi(1+Q / R)$ である. 固体相および流体相内部において散逸されるエネル ギーは，前節と同様に上式において $\delta u_{i}^{s}$ を $-j \omega u_{i}^{s *}, \delta \psi^{f}$ を $-j \omega \psi^{f *}$ と置き換えて実部をとったものであることか ら,$p^{f}=-j \omega \psi^{f}$ を用いると以下のように書くことができる.

$$
\begin{aligned}
& \frac{1}{2} \Re \int_{\Omega}(-j \omega)\left\{\hat{\sigma}_{i j}^{s} \varepsilon_{i j}^{s *}-\rho \omega^{2} u_{i}^{s} u_{i}^{s *}-(\alpha+\tilde{\gamma}) \frac{\partial p^{f}}{\partial x_{i}} u_{i}^{s *}-\alpha p^{f} \frac{\partial u_{i}^{s *}}{\partial x_{i}}\right\} d \Omega=\frac{1}{2} \Re \int_{\Gamma} \sigma_{i j}^{p} n_{j} \dot{u}_{i}^{s *} d \Gamma \\
& \frac{1}{2} \Re \int_{\Omega}(j \omega)\left\{-\frac{\phi^{2}}{\tilde{\rho}_{22} \omega^{2}} \frac{\partial p^{f}}{\partial x_{i}} \frac{\partial p^{f *}}{\partial x_{i}}+\frac{\phi^{2}}{R} p^{f} p^{f *}+(\alpha+\tilde{\gamma}) u_{i}^{s} \frac{\partial p^{f *}}{\partial x_{i}}+\alpha \frac{\partial u_{i}^{s}}{\partial x_{i}} p^{f *}\right\} d \Omega=\frac{1}{2} \Re \int_{\Gamma} \phi\left(\dot{u}_{n}^{f}-\dot{u}_{n}^{s}\right)\left(-p^{f *}\right) d \Gamma
\end{aligned}
$$

式 (24) の左辺は領域内の固体相で散冕されるエネルギー, 右辺は境界から固体相に入力されるエネルギー, 同様 に, 式 (25) の左辺は領域内の流体相で散逸されるエネルギー, 右辺は境界から流体相に入力されるエネルギーを 表している．多孔質材が音場と隣接する場合，その境界においては以下の境界条件が成り立つ.

$$
\begin{aligned}
& (1-\phi) u_{n}^{s}+\phi u_{n}^{f}=-u_{n}^{a} \\
& \sigma_{i j}^{p} p_{j}^{p}=\left(-p^{a}\right) n_{i} \\
& p^{f}=p^{a} \quad\left(\psi^{f}=\psi^{a}\right)
\end{aligned}
$$

これらの関係式を考慮し，固体相および流体相に対して境界から入力されるエネルギーを足し合わせると以下の ように書き直すことができる.

$$
\frac{1}{2} \Re \int_{\Gamma}\left[\sigma_{i j}^{p} p_{j}^{p} \dot{u}_{i}^{s *}-\phi\left(\dot{u}_{n}^{f}-\dot{u}_{n}^{s}\right) p^{f *}\right] d \Gamma=\frac{1}{2} \Re \int_{\Gamma} p^{a} \dot{u}_{i}^{a *} d \Gamma
$$

これより，多孔質材に対して境界から入力されるエネルギーは，多孔質材と音場の境界において隣接する音場が 単位時間になす仕事に等しいことが分かる.

式 (24) の左辺第 1 項は固体相の粘弾性特性によるエネルギー散逸, 式 (25) の左辺第 2 項は, $R$ が熱の固体相へ の散逸による減衰を考慮した流体相の等価体積弾性率 $K^{f}$ で表されていることから，流体相の膨張・圧縮に伴う熱 のエネルギー散逸を表していることが分かる. また, 固体相の速度を $v_{i}^{s}=j \omega u_{i}^{s}$, 流体相の等価流体としての速度 を $v_{i}^{f}=-\frac{1}{\tilde{\rho}_{22} j \omega} \frac{\partial p^{f}}{\partial x_{i}}$ とすると, 式 (24) の左辺第 2, 3 項および式 (25)の左辺第 1, 3 項の和は,

$$
\begin{aligned}
& \frac{1}{2} \Re \int_{\Omega} j \omega\left[\rho \omega^{2} u_{i}^{s} u_{i}^{s *}-\frac{\phi^{2}}{\tilde{\rho}_{22} \omega^{2}} \frac{\partial p^{f}}{\partial x_{i}} \frac{\partial p^{f *}}{\partial x_{i}}+(\alpha+\tilde{\gamma})\left(\frac{\partial p^{f}}{\partial x_{i}} u_{i}^{s *}+u_{i}^{s} \frac{\partial p^{f *}}{\partial x_{i}}\right)\right] d \Omega \\
= & \frac{1}{2} \Re \int_{\Omega} j \omega\left[-\frac{\phi^{2}}{\tilde{\rho}_{22}}\left(\tilde{\rho}_{22} v_{i}^{f}-\rho^{f} v_{i}^{s}\right)\left(\tilde{\rho}_{22}^{*} v_{i}^{f *}-\rho^{f} v_{i}^{s *}\right)\right] d \Omega
\end{aligned}
$$

と書き直すことができる，固体相と流体相の境界における粘性減衰を考慮した等価密度 $\tilde{\rho}_{22}$ を含むことから，こ れは空気の粘性によるエネルギー散逸を表しており，流体相の固体相に対寸る相対速度に依るものであることが 分かる. さらに, $\alpha \approx 1$ である場合には, 式(24)の左辺第 4 項および式(25)の左辺第 4 の和は,

$$
\frac{1}{2} \Re \int_{\Omega} j \omega\left(\alpha p^{f} \frac{\partial u_{i}^{s *}}{\partial x_{i}}+\alpha \frac{\partial u_{i}^{s}}{\partial x_{i}} p^{f *}\right) d \Omega \approx 0
$$

となり, 固体相と流体相の連成に関するエネルギー散逸は, 多孔質材として見るとゼロであることが分かる. 


\subsection{1 垂直入射時の散逸エネルギー}

前節の結果からも分かるように, 多孔質材内部で散逸されるエネルギーの寄与を有限要素法により求めるため には, 要素マトリックスの情報を用いる必要があり, 汎用ソルバーを用いた計算のポスト処理で算出することは難 しいと考えられる.

ここでは，垂直入射吸音率を求める場合に限定し，多孔質吸音材内部を伝播する 1 次元音波に対する波動方程 式の理論解を用いて, 解析的に散逸エネルギーを求める. 理論解の詳細については文献 (Allard and Atalla, 2009) を参照されたい。

多孔質材の固体相および流体相の粒子速度 $\dot{u}^{s}\left(x_{1}\right), \dot{u}^{f}\left(x_{1}\right)$ と応力 $\sigma^{s}\left(x_{1}\right), \sigma^{f}\left(x_{1}\right)$ は, $V_{1}, W_{1}, V_{2}, W_{2}$ を係数とし て，それぞれ以下で表すことができる.

$$
\begin{aligned}
\dot{u}^{s}\left(x_{1}\right) & =\left(V_{1} e^{-j k_{1} x_{1}}-W_{1} e^{j k_{1} x_{1}}\right)+\left(V_{2} e^{-j k_{2} x_{1}}-W_{2} e^{j k_{2} x_{1}}\right) \\
\dot{u}^{f}\left(x_{1}\right) & =\mu_{1}\left(V_{1} e^{-j k_{1} x_{1}}-W_{1} e^{j k_{1} x_{1}}\right)+\mu_{2}\left(V_{2} e^{-j k_{2} x_{1}}-W_{2} e^{j k_{2} x_{1}}\right) \\
-\sigma^{s}\left(x_{1}\right) & =Z_{1}^{s}\left(V_{1} e^{-j k_{1} x_{1}}+W_{1} e^{j k_{1} x_{1}}\right)+Z_{2}^{s}\left(V_{2} e^{-j k_{2} x_{1}}+W_{2} e^{j k_{2} x_{1}}\right) \\
-\sigma^{f}\left(x_{1}\right) & =\phi Z_{1}^{f} \mu_{1}\left(V_{1} e^{-j k_{1} x_{1}}+W_{1} e^{j k_{1} x_{1}}\right)+\phi Z_{2}^{f} \mu_{2}\left(V_{2} e^{-j k_{2} x_{1}}+W_{2} e^{j k_{2} x_{1}}\right)
\end{aligned}
$$

ここで,

$$
\lambda_{1}^{2}, \lambda_{2}^{2}=\frac{1}{2}\left[\left(R \tilde{\rho}_{11}+P \tilde{\rho}_{22}-2 Q \tilde{\rho}_{12}\right) \pm \sqrt{\left(R \tilde{\rho}_{11}+P \tilde{\rho}_{22}-2 Q \tilde{\rho}_{12}\right)^{2}-4\left(P R-Q^{2}\right)\left(\tilde{\rho}_{11} \tilde{\rho}_{22}-\tilde{\rho}_{12}^{2}\right)}\right]
$$

として $, k_{m}, \mu_{m}, Z_{m}^{s}, Z_{m}^{f}(m=1,2)$ は次式で与えられる.

$$
k_{m}^{2}=\frac{\omega^{2}}{P R-Q^{2}} \lambda_{m}^{2}, \mu_{m}=\frac{P k_{m}^{2}-\tilde{\rho}_{11} \omega^{2}}{\tilde{\rho}_{12} \omega^{2}-Q k_{m}^{2}}, Z_{m}^{s}=\left(P+\mu_{m} Q\right) \frac{k_{m}}{\omega}, Z_{m}^{f}=\left(R+\frac{Q}{\mu_{m}}\right) \frac{k_{m}}{\phi \omega}
$$

多孔質吸音材内部における散逸エネルギーは，式(24) および式 (25) において $i=1, j=1$ として以下のように書く ことができる.

$$
\begin{aligned}
& \frac{1}{2} \Re \int_{\Omega}(-j \omega)\left\{\hat{\sigma}_{11}^{s} \varepsilon_{11}^{s *}-\rho \omega^{2} u_{1}^{s} u_{1}^{s *}-(\alpha+\tilde{\gamma}) \frac{\partial p^{f}}{\partial x_{1}} u_{1}^{s *}-\alpha p^{f} \frac{\partial u_{1}^{s *}}{\partial x_{1}}\right\} d \Omega=\frac{1}{2} \Re \int_{\Gamma} \sigma_{11}^{p} n_{1}^{p} \dot{u}_{1}^{s *} d \Gamma \\
& \frac{1}{2} \Re \int_{\Omega}(j \omega)\left\{-\frac{\phi^{2}}{\tilde{\rho}_{22} \omega^{2}} \frac{\partial p^{f}}{\partial x_{1}} \frac{\partial p^{f *}}{\partial x_{1}}+\frac{\phi^{2}}{R} p^{f} p^{f *}+(\alpha+\tilde{\gamma}) u_{1}^{s} \frac{\partial p^{f *}}{\partial x_{1}}+\alpha \frac{\partial u_{1}^{s}}{\partial x_{1}} p^{f *}\right\} d \Omega=\frac{1}{2} \Re \int_{\Gamma} \phi\left(\dot{u}_{n}^{f}-\dot{u}_{n}^{s}\right)\left(-p^{f *}\right) d \Gamma
\end{aligned}
$$

上式に理論解 (33) (36) を代入し, 吸音材の厚さを $d$ として積分すると, 式 (39) の左辺第 1 項から第 4 項に関 する定積分は以下のように算出できる.

$$
\begin{aligned}
\Pi_{s 1} & =\int_{0}^{d} \frac{1}{2} \Re(-j \omega)\left(\hat{\sigma}_{11}^{s} \varepsilon_{11}^{s *}\right) d x_{1} \\
& =\frac{1}{2} \Re(-j \omega)\left[\left(z_{1}^{s}-\frac{Q}{R} \phi z_{1}^{f} \mu_{1}\right) \frac{k_{1}^{*}}{\omega} I_{1}+\left(z_{1}^{s}-\frac{Q}{R} \phi z_{1}^{f} \mu_{1}\right) \frac{k_{2}^{*}}{\omega} I_{2}+\left(z_{2}^{s}-\frac{Q}{R} \phi z_{2}^{f} \mu_{2}\right) \frac{k_{1}^{*}}{\omega} I_{3}+\left(z_{2}^{s}-\frac{Q}{R} \phi z_{2}^{f} \mu_{2}\right) \frac{k_{2}^{*}}{\omega} I_{4}\right] \\
\Pi_{s 2} & =\int_{0}^{d} \frac{1}{2} \Re(j \omega) \rho \omega^{2} u_{1}^{s} u_{1}^{s *} d x_{1}=\frac{1}{2} \Re(j \omega) \rho \omega^{2} \frac{1}{\omega^{2}}\left(J_{1}+J_{2}+J_{3}+J_{4}\right) \\
\Pi_{s 3} & =\int_{0}^{d} \frac{1}{2} \Re(j \omega)(\alpha+\tilde{\gamma}) \frac{\partial p^{f}}{\partial x_{1}} u_{1}^{s *} d x_{1}=\frac{1}{2} \Re(j \omega)(\alpha+\tilde{\gamma})\left[\frac{k_{1} z_{1}^{f} \mu_{1}}{\omega}\left(J_{1}+J_{2}\right)+\frac{k_{2} z_{2}^{f} \mu_{2}}{\omega}\left(J_{3}+J_{4}\right)\right] \\
\Pi_{s 4} & =\int_{0}^{d} \frac{1}{2} \Re(j \omega) \alpha p^{f} \frac{\partial u_{1}^{s *}}{\partial x_{1}} d x_{1}=\frac{1}{2} \Re(j \omega) \alpha\left[-\frac{z_{1}^{f} \mu_{1} k_{1}^{*}}{\omega} I_{1}-\frac{z_{1}^{f} \mu_{1} k_{2}^{*}}{\omega} I_{2}-\frac{z_{2}^{f} \mu_{2} k_{1}^{*}}{\omega} I_{3}-\frac{z_{2}^{f} \mu_{2} k_{2}^{*}}{\omega} I_{4}\right]
\end{aligned}
$$


同様に，式(40)の左辺第 1 項から第 4 項に関する定積分は以下のように算出できる.

$$
\begin{aligned}
\Pi_{f 1} & =\int_{0}^{d} \frac{1}{2} \Re(j \omega)\left(-\frac{\phi^{2}}{\tilde{\rho}_{22} \omega^{2}} \frac{\partial p^{f}}{\partial x_{1}} \frac{\partial p^{f *}}{\partial x_{1}}\right) d x_{1} \\
& =\frac{1}{2} \Re(j \omega)\left(-\frac{\phi^{2}}{\tilde{\rho}_{22} \omega^{2}}\right)\left[k_{1} z_{1}^{f} \mu_{1} k_{1}^{*} z_{1}^{f *} \mu_{1}^{*} J_{1}+k_{1} z_{1}^{f} \mu_{1} k_{2}^{*} z_{2}^{f *} \mu_{2}^{*} J_{2}+k_{2} z_{2}^{f} \mu_{2} k_{1}^{*} z_{1}^{f *} \mu_{1}^{*} J_{3}+k_{2} z_{2}^{f} \mu_{2} k_{2}^{*} z_{2}^{f *} \mu_{2}^{*} J_{4}\right] \\
\Pi_{f 2} & =\int_{0}^{d} \frac{1}{2} \Re(j \omega) \frac{\phi^{2}}{R} p^{f} p^{f *} d x_{1}=\frac{1}{2} \Re(j \omega) \frac{\phi^{2}}{R}\left[z_{1}^{f} \mu_{1} z_{1}^{f *} \mu_{1}^{*} I_{1}+z_{1}^{f} \mu_{1} z_{2}^{f *} \mu_{2}^{*} I_{2}+z_{2}^{f} \mu_{2} z_{1}^{f *} \mu_{1}^{*} I_{3}+z_{2}^{f} \mu_{2} z_{2}^{f *} \mu_{2}^{*} I_{4}\right] \\
\Pi_{f 3} & =\int_{0}^{d} \frac{1}{2} \Re(j \omega)(\alpha+\tilde{\gamma}) u_{1}^{s} \frac{\partial p^{f *}}{\partial x_{1}} d x_{1}=\frac{1}{2} \Re(j \omega)(\alpha+\tilde{\gamma})\left[\frac{k_{1}^{*} z_{1}^{f *} \mu_{1}^{*}}{\omega}\left(J_{1}+J_{3}\right)+\frac{k_{2}^{*} z_{2}^{f *} \mu_{2}^{*}}{\omega}\left(J_{2}+J_{4}\right)\right] \\
\Pi_{f 4} & =\int_{0}^{d} \frac{1}{2} \Re(j \omega) \alpha \frac{\partial u_{1}^{s}}{\partial x_{1}} p^{f *} d x_{1}=\frac{1}{2} \Re(j \omega) \alpha\left[-\frac{k_{1} z_{1}^{f *} \mu_{1}^{*}}{\omega} I_{1}-\frac{k_{1} z_{2}^{f *} \mu_{2}^{*}}{\omega} I_{2}-\frac{k_{2} z_{1}^{f *} \mu_{1}^{*}}{\omega} I_{3}-\frac{k_{2} z_{2}^{f *} \mu_{2}^{*}}{\omega} I_{4}\right]
\end{aligned}
$$

なお，定積分 $I_{i}, J_{i}(i=1,2,3,4)$ は以下のとおりである.

$$
\begin{aligned}
& I_{1}=\left[\frac{V_{1} V_{1}^{*}}{-j\left(k_{1}-k_{1}^{*}\right)} e^{-j\left(k_{1}-k_{1}^{*}\right) x_{1}}+\frac{W_{1} V_{1}^{*}}{j\left(k_{1}+k_{1}^{*}\right)} e^{j\left(k_{1}+k_{1}^{*}\right) x_{1}}+\frac{V_{1} W_{1}^{*}}{-j\left(k_{1}+k_{1}^{*}\right)} e^{-j\left(k_{1}+k_{1}^{*}\right) x_{1}}+\frac{W_{1} W_{1}^{*}}{j\left(k_{1}-k_{1}^{*}\right)} e^{j\left(k_{1}-k_{1}^{*}\right) x_{1}}\right]_{0}^{d} \\
& I_{2}=\left[\frac{V_{1} V_{2}^{*}}{-j\left(k_{1}-k_{2}^{*}\right)} e^{-j\left(k_{1}-k_{2}^{*}\right) x_{1}}+\frac{W_{1} V_{2}^{*}}{j\left(k_{1}+k_{2}^{*}\right)} e^{j\left(k_{1}+k_{2}^{*}\right) x_{1}}+\frac{V_{1} W_{2}^{*}}{-j\left(k_{1}+k_{2}^{*}\right)} e^{-j\left(k_{1}+k_{2}^{*}\right) x_{1}}+\frac{W_{1} W_{2}^{*}}{j\left(k_{1}-k_{2}^{*}\right)} e^{j\left(k_{1}-k_{2}^{*}\right) x_{1}}\right]_{0}^{d} \\
& I_{3}=\left[\frac{V_{2} V_{1}^{*}}{-j\left(k_{2}-k_{1}^{*}\right)} e^{-j\left(k_{2}-k_{1}^{*}\right) x_{1}}+\frac{W_{2} V_{1}^{*}}{j\left(k_{2}+k_{1}^{*}\right)} e^{j\left(k_{2}+k_{1}^{*}\right) x_{1}}+\frac{V_{2} W_{1}^{*}}{-j\left(k_{2}+k_{1}^{*}\right)} e^{-j\left(k_{2}+k_{1}^{*}\right) x_{1}}+\frac{W_{2} W_{1}^{*}}{j\left(k_{2}-k_{1}^{*}\right)} e^{j\left(k_{2}-k_{1}^{*}\right) x_{1}}\right]_{0}^{d} \\
& I_{4}=\left[\frac{V_{2} V_{2}^{*}}{-j\left(k_{2}-k_{2}^{*}\right)} e^{-j\left(k_{2}-k_{2}^{*}\right) x_{1}}+\frac{W_{2} V_{2}^{*}}{j\left(k_{2}+k_{2}^{*}\right)} e^{j\left(k_{2}+k_{2}^{*}\right) x_{1}}+\frac{V_{2} W_{2}^{*}}{-j\left(k_{2}+k_{2}^{*}\right)} e^{-j\left(k_{2}+k_{2}^{*}\right) x_{1}}+\frac{W_{2} W_{2}^{*}}{j\left(k_{2}-k_{2}^{*}\right)} e^{j\left(k_{2}-k_{2}^{*}\right) x_{1}}\right]_{0}^{d} \\
& J_{1}=\left[\frac{V_{1} V_{1}^{*}}{-j\left(k_{1}-k_{1}^{*}\right)} e^{-j\left(k_{1}-k_{1}^{*}\right) x_{1}}-\frac{W_{1} V_{1}^{*}}{j\left(k_{1}+k_{1}^{*}\right)} e^{j\left(k_{1}+k_{1}^{*}\right) x_{1}}-\frac{V_{1} W_{1}^{*}}{-j\left(k_{1}+k_{1}^{*}\right)} e^{-j\left(k_{1}+k_{1}^{*}\right) x_{1}}+\frac{W_{1} W_{1}^{*}}{j\left(k_{1}-k_{1}^{*}\right)} e^{j\left(k_{1}-k_{1}^{*}\right) x_{1}}\right]_{0}^{d} \\
& J_{2}=\left[\frac{V_{1} V_{2}^{*}}{-j\left(k_{1}-k_{2}^{*}\right)} e^{-j\left(k_{1}-k_{2}^{*}\right) x_{1}}-\frac{W_{1} V_{2}^{*}}{j\left(k_{1}+k_{2}^{*}\right)} e^{j\left(k_{1}+k_{2}^{*}\right) x_{1}}-\frac{V_{1} W_{2}^{*}}{-j\left(k_{1}+k_{2}^{*}\right)} e^{-j\left(k_{1}+k_{2}^{*}\right) x_{1}}+\frac{W_{1} W_{2}^{*}}{j\left(k_{1}-k_{2}^{*}\right)} e^{j\left(k_{1}-k_{2}^{*}\right) x_{1}}\right]_{0}^{d} \\
& J_{3}=\left[\frac{V_{2} V_{1}^{*}}{-j\left(k_{2}-k_{1}^{*}\right)} e^{-j\left(k_{2}-k_{1}^{*}\right) x_{1}}-\frac{W_{2} V_{1}^{*}}{j\left(k_{2}+k_{1}^{*}\right)} e^{j\left(k_{2}+k_{1}^{*}\right) x_{1}}-\frac{V_{2} W_{1}^{*}}{-j\left(k_{2}+k_{1}^{*}\right)} e^{-j\left(k_{2}+k_{1}^{*}\right) x_{1}}+\frac{W_{2} W_{1}^{*}}{j\left(k_{2}-k_{1}^{*}\right)} e^{j\left(k_{2}-k_{1}^{*}\right) x_{1}}\right]_{0}^{d} \\
& J_{4}=\left[\frac{V_{2} V_{2}^{*}}{-j\left(k_{2}-k_{2}^{*}\right)} e^{-j\left(k_{2}-k_{2}^{*}\right) x_{1}}-\frac{W_{2} V_{2}^{*}}{j\left(k_{2}+k_{2}^{*}\right)} e^{j\left(k_{2}+k_{2}^{*}\right) x_{1}}-\frac{V_{2} W_{2}^{*}}{-j\left(k_{2}+k_{2}^{*}\right)} e^{-j\left(k_{2}+k_{2}^{*}\right) x_{1}}+\frac{W_{2} W_{2}^{*}}{j\left(k_{2}-k_{2}^{*}\right)} e^{j\left(k_{2}-k_{2}^{*}\right) x_{1}}\right]_{0}^{d}
\end{aligned}
$$

以上より，多孔質吸音材内部で散逸される総エネルギー $\Pi_{d s p}$ は次式で求められる.

$$
\Pi_{d s p}=\sum_{i=1}^{4} \Pi_{s i}+\sum_{i=1}^{4} \Pi_{f i}
$$

なお， $\alpha \approx 1$ の場合には，

$$
\Pi_{s 4}+\Pi_{f 4} \approx 0
$$

となる。 また，固体相の構造減衰による散逸エネルギー $\Pi_{s t r}$, 流体相の粘性減衰による散逸エネルギー $\Pi_{v s c}$ およ び流体相の熱拡散による散逸エネルギー $\Pi_{t h r}$ は, 以下のように求めることができる.

$$
\begin{aligned}
\Pi_{s t r} & =\Pi_{s 1} \\
\Pi_{v s c} & =\Pi_{s 2}+\Pi_{s 3}+\Pi_{f 1}+\Pi_{f 3} \\
\Pi_{t h r} & =\Pi_{f 2}
\end{aligned}
$$




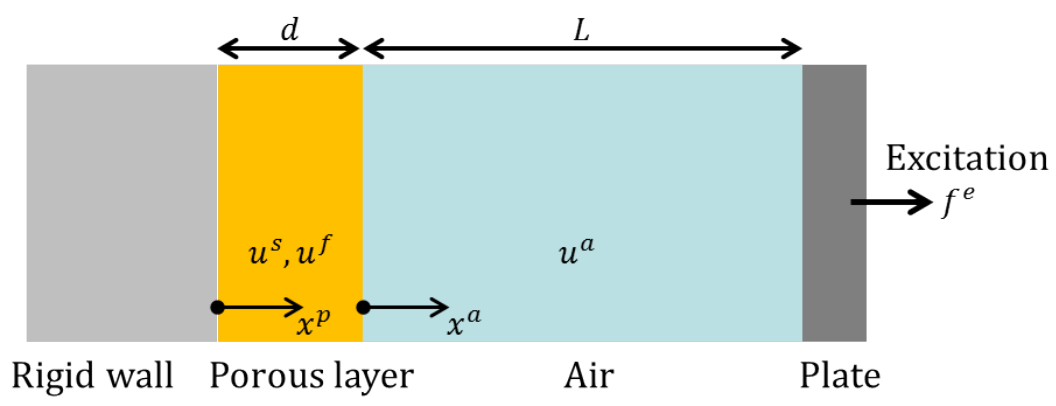

Fig. 2 Schematic view of impedance tube model. Porous material is located at the end of the left side, and the plate to be excited is located at the right side of the impedance tube. One dimensional plane wave is assumed to be propagated inside of the tube.

\section{4. 音響管内に設けた多孔質吸音材内部における散逸エネルギー}

ここでは，図 2 に示すような 1 次元音響管を模した系を考える. 左端に厚さ $d$ の多孔質吸音材があり, 長さ $L$ の音場を介して，右端にスピーカーを模擬した剛板があるものとする．管内音場における粒子速度 $\dot{u}^{a}$ と応力 $\sigma^{a}$ は， $V^{a}, W^{a}$ を未知係数として，それぞれ以下で表すことができる.

$$
\begin{aligned}
\dot{u}^{a}\left(x^{a}\right) & =\left(V^{a} e^{-j k_{0} x^{a}}-W^{a} e^{j k_{0} x^{a}}\right) \\
-\sigma^{a}\left(x^{a}\right) & =Z_{0}\left(V^{a} e^{-j k_{0} x^{a}}+W^{a} e^{j k_{0} x^{a}}\right)
\end{aligned}
$$

ここで， $x^{a}$ は管内音場の左端を原点にとり管軸方向に沿って設けた座標系， $Z_{0}$ は空気の音響特性インピーダ ンスで, 空気の質量密度を $\rho_{0}$, 空気中の音速を $c_{0}$ として $Z_{0}=\rho_{0} c_{0}, k_{0}=\omega / c_{0}$ である. なお, 音圧 $p^{a}\left(x^{a}\right)$ は $p^{a}\left(x^{a}\right)=-\sigma^{a}\left(x^{a}\right)$ で求めることができる.

多孔質材内の固体相および流体相における粒子速度 $\dot{u}^{s}, \dot{u}^{f}$ と応力 $\sigma^{s}, \sigma^{f}$ は, 前節で示したように $V_{1}, W_{1}, V_{2}, W_{2}$ を未知係数としてそれぞれ次式で表すことができる.

$$
\begin{aligned}
\dot{u}^{s}\left(x^{p}\right) & =\left(V_{1} e^{-j k_{1} x^{p}}-W_{1} e^{j k_{1} x^{p}}\right)+\left(V_{2} e^{-j k_{2} x^{p}}-W_{2} e^{j k_{2} x^{p}}\right) \\
\dot{u}^{f}\left(x^{p}\right) & =\mu_{1}\left(V_{1} e^{-j k_{1} x^{p}}-W_{1} e^{j k_{1} x^{p}}\right)+\mu_{2}\left(V_{2} e^{-j k_{2} x^{p}}-W_{2} e^{j k_{2} x^{p}}\right) \\
-\sigma^{s}\left(x^{p}\right) & =Z_{1}^{s}\left(V_{1} e^{-j k_{1} x^{p}}+W_{1} e^{j k_{1} x^{p}}\right)+Z_{2}^{s}\left(V_{2} e^{-j k_{2} x^{p}}+W_{2} e^{j k_{2} x^{p}}\right) \\
-\sigma^{f}\left(x^{p}\right) & =\phi Z_{1}^{f} \mu_{1}\left(V_{1} e^{-j k_{1} x^{p}}+W_{1} e^{j k_{1} x^{p}}\right)+\phi Z_{2}^{f} \mu_{2}\left(V_{2} e^{-j k_{2} x^{p}}+W_{2} e^{j k_{2} x^{p}}\right)
\end{aligned}
$$

ここで， $x^{p}$ は多孔質吸音材の左端を原点にとり，管軸方向に沿って設けた座標系である.

まず， $x^{p}=0$ において粒子速度および応力の連続条件により，以下の関係式を得ることができる.

$$
\begin{aligned}
& \left(1-\phi_{1}\right) \dot{u}_{1}^{s}(0)+\phi_{1} \dot{u}_{1}^{f}(0)=0 \\
& \phi_{1} \sigma_{1}^{s}(0)-\left(1-\phi_{1}\right) \sigma_{1}^{f}(0)=0
\end{aligned}
$$

なお，剛壁と多孔質吸音材は接着していないとする. 次に, $x^{p}=d$ あるいは $x^{a}=0$ において多孔質吸音材と空気 の粒子速度および応力・音圧の連続条件より, 以下の関係式を得ることができる.

$$
\begin{aligned}
& (1-\phi) \dot{u}_{1}^{s}(d)+\phi \dot{u}_{1}^{f}(d)=\dot{u}^{a}(0) \\
& \sigma_{1}^{s}(d)+\sigma_{1}^{f}(d)=\sigma^{a}(0) \\
& \frac{-\sigma_{1}^{f}(d)}{\phi}=-\sigma^{a}(0)
\end{aligned}
$$

最後に, $x^{a}=L$ において, 速度の連続条件および剛板に関する運動方程式より, 以下の関係式を得ることができる.

$$
\begin{aligned}
& \dot{u}^{a}(L)=\dot{u}^{e} \\
& m^{e} \frac{\partial \dot{u}^{e}}{\partial t}=f^{e}-\sigma^{a}(L)
\end{aligned}
$$


ここで, $\dot{u}^{e}$ は剛板の振動速度, $m^{e}$ は剛板の面密度, $f^{e}$ は剛板に作用する単位面積あたりの外力である.

式 (66) から式 (69) の一般解を, 式 (70) から式 (76) の境界条件式に代入しマトリックスで表すと, 以下のよう に書くことができる.

$$
A X=F
$$

$$
\boldsymbol{A}=\left[\begin{array}{ll}
\boldsymbol{A}_{1} & \boldsymbol{A}_{2}
\end{array}\right]
$$

$$
\boldsymbol{A}_{1}=\left[\begin{array}{cccc}
\left(1-\phi_{1}+\phi_{1} \mu_{1}\right) & -\left(1-\phi_{1}+\phi_{1} \mu_{1}\right) & \left(1-\phi_{1}+\phi_{1} \mu_{2}\right) & -\left(1-\phi_{1}+\phi_{1} \mu_{2}\right) \\
\phi_{1} Z_{1}^{s}-\left(1-\phi_{1}\right) \phi_{1} Z_{1}^{f} \mu_{1} & \phi_{1} Z_{1}^{s}-\left(1-\phi_{1}\right) \phi_{1} Z_{1}^{f} \mu_{1} & \phi_{1} Z_{2}^{s}-\left(1-\phi_{1}\right) \phi_{1} Z_{2}^{f} \mu_{2} \phi_{1} Z_{2}^{s}-\left(1-\phi_{1}\right) \phi_{1} Z_{2}^{f} \mu_{2} \\
\left(1-\phi_{1}+\phi_{1} \mu_{1}\right) e^{-j k_{1} d} & -\left(1-\phi_{1}+\phi_{1} \mu_{1}\right) e^{j k_{1} d} & \left(1-\phi_{1}+\phi_{1} \mu_{2}\right) e^{-j k_{2} d} & -\left(1-\phi_{1}+\phi_{1} \mu_{2}\right) e^{j k_{2} d} \\
\left(Z_{1}^{s}+\phi_{1} Z_{1}^{f} \mu_{1}\right) e^{-j k_{1} d} & \left(Z_{1}^{s}+\phi_{1} Z_{1}^{f} \mu_{1}\right) e^{j k_{1} d} & \left(Z_{2}^{s}+\phi_{1} Z_{2}^{f} \mu_{2}\right) e^{-j k_{2} d} & \left(Z_{2}^{s}+\phi_{1} Z_{2}^{f} \mu_{2}\right) e^{j k_{2} d} \\
Z_{1}^{f} \mu_{1} e^{-j k_{1} d} & Z_{1}^{f} \mu_{1} e^{j k_{1} d} & Z_{2}^{f} \mu_{2} e^{-j k_{2} d} & Z_{2}^{f} \mu_{2} e^{j k_{2} d} \\
0 & 0 & 0 & 0 \\
0 & 0 & 0 & 0
\end{array}\right]
$$

$$
\boldsymbol{A}_{2}=\left[\begin{array}{ccc}
0 & 0 & 0 \\
0 & 0 & 0 \\
-1 & 1 & 0 \\
-Z_{0} & -Z_{0} & 0 \\
-Z_{0} & -Z_{0} & 0 \\
e^{-j k_{0} L} & -e^{j k_{0} L} & -1 \\
-Z_{0} e^{-j k_{0} L}-Z_{0} e^{j k_{0} L} & Z^{e}
\end{array}\right], \boldsymbol{X}=\left[\begin{array}{c}
V_{1} \\
W_{1} \\
V_{2} \\
W_{2} \\
V^{a} \\
W^{a} \\
\dot{u}^{e}
\end{array}\right], \boldsymbol{F}=\left[\begin{array}{c}
0 \\
0 \\
0 \\
0 \\
0 \\
0 \\
f^{e}
\end{array}\right]
$$

ただし， $Z^{e}=j \omega m^{e}$ である．これを解くことで係数 $V_{1}, W_{1}, V_{2}, W_{2}, V^{a}, W^{a}$ を得ることができる．また，式(39) お よび式 (40)より多孔質材内部で散逸されるエネルギーを求めることができる.

また，多孔質吸音材へ入射する音波の音響エネルギー $\Pi_{i n n}$ は

$$
\Pi_{\text {inn }}=\frac{1}{2} \Re\left[p_{\text {inc }}(0) \dot{u}_{n}^{*}(0)\right]=\frac{1}{2} Z^{a} W^{a 2}
$$

で求めることができ, 多孔質吸音材の吸音率 $\alpha_{a b s}$ は次式で求めることができる.

$$
\alpha_{a b s}=\frac{\Pi_{d s p}}{\Pi_{i n n}}
$$

\section{5. 数 值 検 証}

自動車の防音材として使用されている繊維材, 高密度に圧縮した繊維材, ポリウレタンフォームの 3 種類の多 孔質吸音材を対象に，垂直入射吸音率に対する各散逸エネルギーの寄与を分析する. 各多孔質吸音材の Biot のパ ラメータは表 1 に示寸とおりである. また，材料の厚さはいずれも $20 \mathrm{~mm}$ とする.

まず, 散逸エネルギーを与える式の検証のため, 式 (82) を用いて入射する音波の音響エネルギーと散逸エネ ルギーの比より求めた吸音率と, 音響管内の 2 点の音圧 $p_{1}, p_{2}$ を用いて次式により求めた吸音率を比較する.

$$
\alpha_{a b s}=1-\left|R_{s}\right|^{2}, \quad R_{s}=\frac{e^{-j k_{0}\left(l_{2}-l_{1}\right)}-\frac{p_{1}}{p_{2}}}{\frac{p_{1}}{p_{2}}-e^{j k_{0}\left(l_{2}-l_{1}\right)}} e^{j 2 k_{0} l_{2}}
$$


Yamamoto, Katsura and Kubota, Transactions of the JSME (in Japanese), Vol.86, No.887 (2020)

Table 1 Biot's parameters of sound-absorbing poroelastic media. Soft felt, compressed felt and polyurethane foam are utilized to demonstrate the expressions of the energy dissipated inside the porous media.

\begin{tabular}{lccc}
\hline & Soft felt & Compressed felt & Polyurethane foam \\
\hline \hline Young's modulus $E$ & $18.88 \mathrm{kPa}$ & $44.28 \mathrm{kPa}$ & $185.1 \mathrm{kPa}$ \\
\hline Poisson's ratio $v$ & 0.0001 & 0.0001 & 0.322 \\
\hline Mass density $\rho$ & $47.07 \mathrm{~kg} / \mathrm{m}^{3}$ & $220.4 \mathrm{~kg} / \mathrm{m}^{3}$ & $42.57 \mathrm{~kg} / \mathrm{m}^{3}$ \\
\hline Loss factor $\eta$ & 0.055 & 0.1312 & 0.1176 \\
\hline \hline Porosity $\phi$ & 0.9695 & 0.8916 & 0.9755 \\
\hline Tortuosity $\alpha_{\infty}$ & 1.00 & 1.44 & 2.12 \\
\hline Air flow resistivity $\sigma$ & $10.16 \mathrm{kNs} / \mathrm{m}^{4}$ & $329.0 \mathrm{kNs} / \mathrm{m}^{4}$ & $52.61 \mathrm{kNs} / \mathrm{m}^{4}$ \\
\hline Viscous characteristic length $\Lambda$ & $88.3 \mu \mathrm{m}$ & $11.2 \mu \mathrm{m}$ & $17.3 \mu \mathrm{m}$ \\
\hline Thermal characteristic length $\Lambda^{\prime}$ & $227 . \mu \mathrm{m}$ & $34.6 \mu \mathrm{m}$ & $321.7 \mu \mathrm{m}$ \\
\hline
\end{tabular}

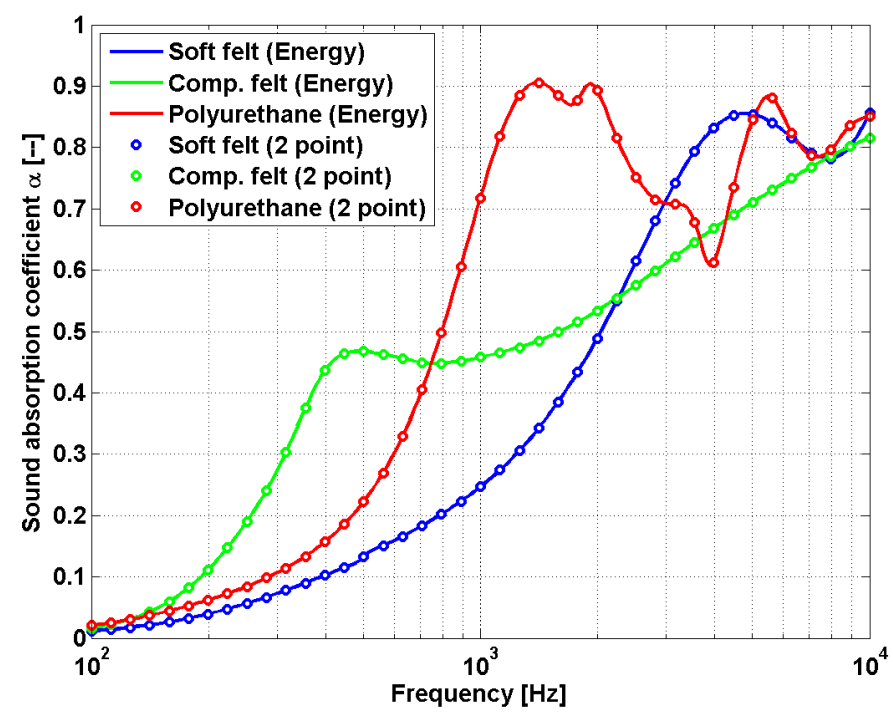

Fig. 3 Sound absorption coefficients for normal incidence. Solid lines give sound absorption coefficients obtained by the ratio of dissipated energy to input energy as shown by Eq. (82). Dots give sound absorption coefficients obtained by acoustic pressures at 2 points as shown by Eq. (83). Blue represents soft felt, green compressed felt, and red polyurethane foam. Sound absorption coefficients obtained by Eq. (82) agree well those by Eq. (83).

ここで, $l_{1}, l_{2}$ は多孔質吸音材表面から音圧算出点までの距離であり, ここでは, $l_{1}=30 \mathrm{~mm}, l_{2}=50 \mathrm{~mm}$ とした.

図 3 に示寸ように, 散逸エネルギーより求めた吸音率と, 音響管内の 2 点の音圧 $p_{1}, p_{2}$ を用いて式 (83) から求 めた吸音率は一致している，これより，散逸エネルギーを求める本手法の妥当性を示寸ことができた.

次に，各散逸エネルギーの寄与を求め，その妥当性を検証する．図４は䋊維材料を用いた場合で，(a) は入射音 響エネルギーに対する各散逸エネルギーの割合，(b) は全散逸エネルギーに対する各散逸エネルギーの割合を示し ている. $1 \mathrm{kHz}$ までは熱による散逸の寄与が大きく, それより高い周波数では粘性による散逸の寄与が大きい. 構 造減衰による散逸の寄与は, $10 \mathrm{kHz}$ までの全周波数範囲において非常に小さい. $500 \mathrm{~Hz}$ で構造減衰による散逸の 寄与が若干大きくなっているのは, 材料厚さ方向の固体相の共振に起因寸る. また図 5 は, 多孔質材の $x^{p}=2 / 3 d$ における固体相および流体相の振動速度を示している．なお，音響管内の共鳴の影響を排除するため $x^{a}=0$ にお 


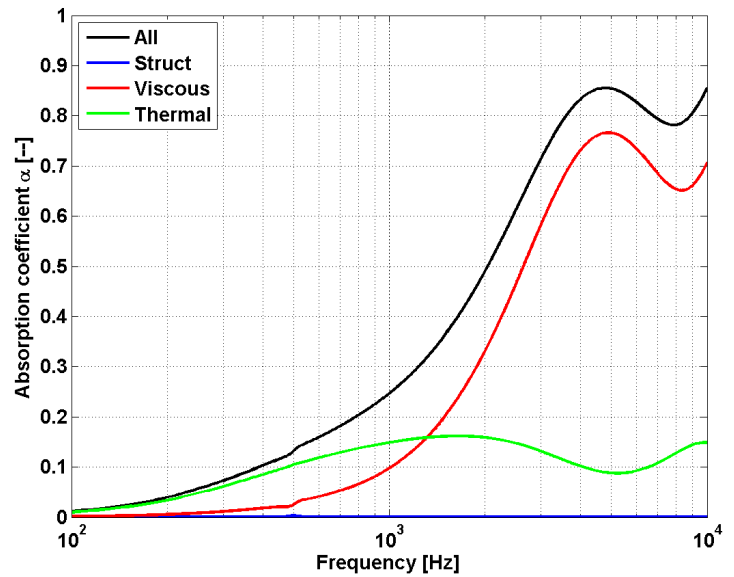

(a) Normalized by incident energy

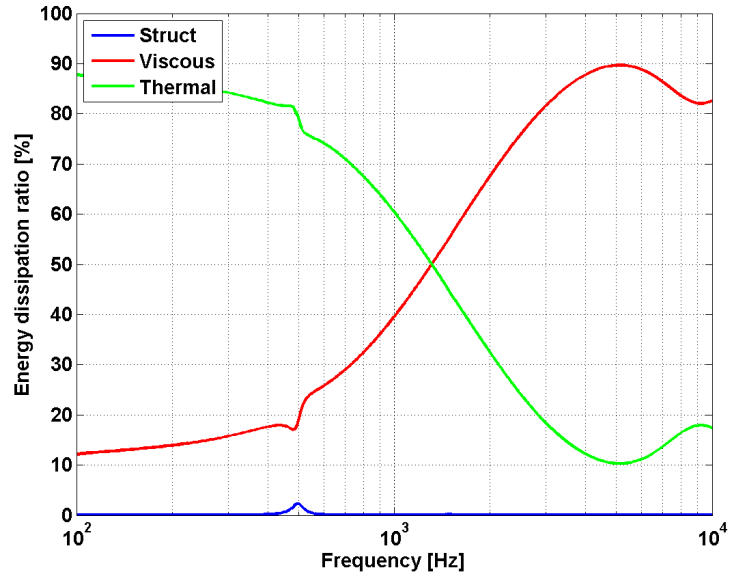

(b) Normalized by total dissipated energy

Fig. 4 Dissipated energy in soft felt. Left figure shows dissipated energies normalized by incident energy. Right figure shows dissipated energies normalized by total dissipated energy. Blue represents energy dissipated by structural damping, red by viscosity of air, green by thermal conduction. Black shows total dissipated energy. Acoustic energy is mainly dissipated by thermal conduction in low frequency range below $1 \mathrm{kHz}$, and by viscous damping in high frequency range above $2 \mathrm{kHz}$.

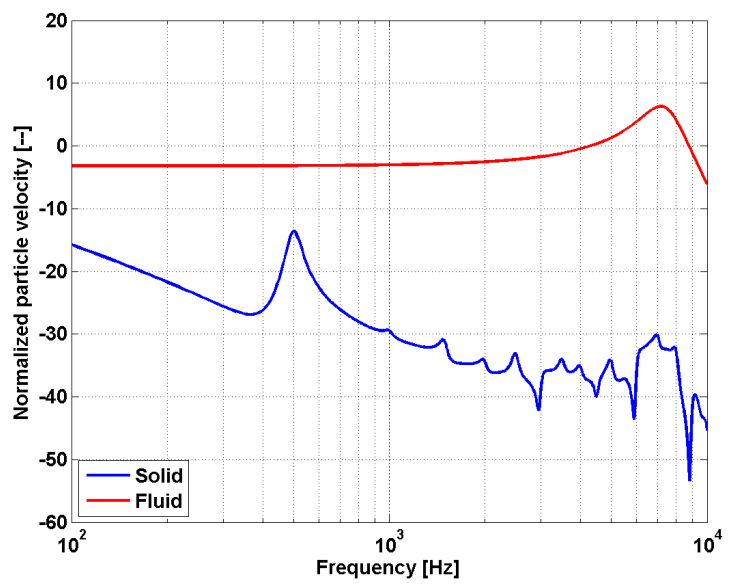

Fig. 5 Vibration velocity of fluid phase in red and solid phase in blue. Vibration velocity of solid phase become large due to the resonance at $500 \mathrm{~Hz}$ and vibration velocity of fluid phase relative to velocity of solid phase become small, which causes the dip of dissipated energy by viscous damping at $500 \mathrm{~Hz}$ as shown in Fig. 4(b).

ける音場の粒子速度で正規化している．図より，500 Hzでは固体相の振動速度が大きくなっていることが分かる。 これにより流体相の固体相に対する相対速度が小さくなり，粘性による散逸エネルギーが小さくなったと考えら れる.

図 6 および図 7 は，それぞれ圧縮した繊維材料，ポリウレタンフォームを用いた場合であり，(a) は入射音響エネ ルギーに対する各散逸エネルギーの割合，(b) は全散逸エネルギーに対する各散逸エネルギーの割合を示している. 圧縮した繊維材料では，10 kHz までの周波数範囲において粘性による散逸の寄与が大きい. ポリウレタンフォー ムは，䋊維材と類似した散逸エネルギーの寄与を示しているが，固体相の構造減衰による散逸の寄与が若干大き くなっている. 


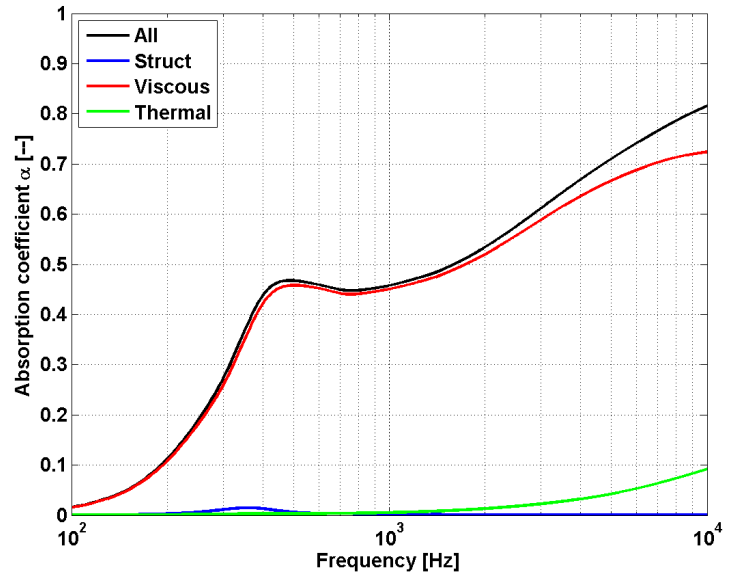

(a) Normalized by incident energy

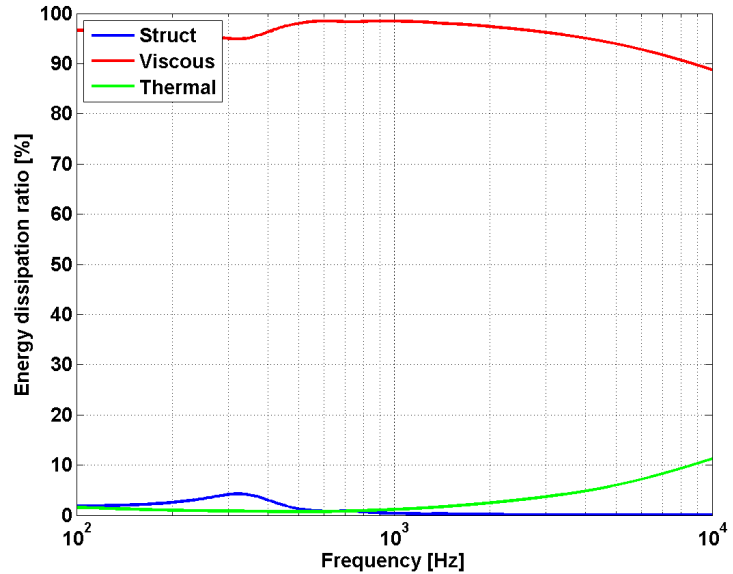

(b) Normalized by total dissipated energy

Fig. 6 Dissipated energy in compressed felt. Left figure shows dissipated energies normalized by incident energy. Right figure shows dissipated energies normalized by total dissipated energy. Blue represents energy dissipated by structural damping, red by viscosity of air, green by thermal conduction. Black shows total dissipated energy. Acoustic energy is mainly dissipated by viscous damping in all the frequency range up to $10 \mathrm{kHz}$.

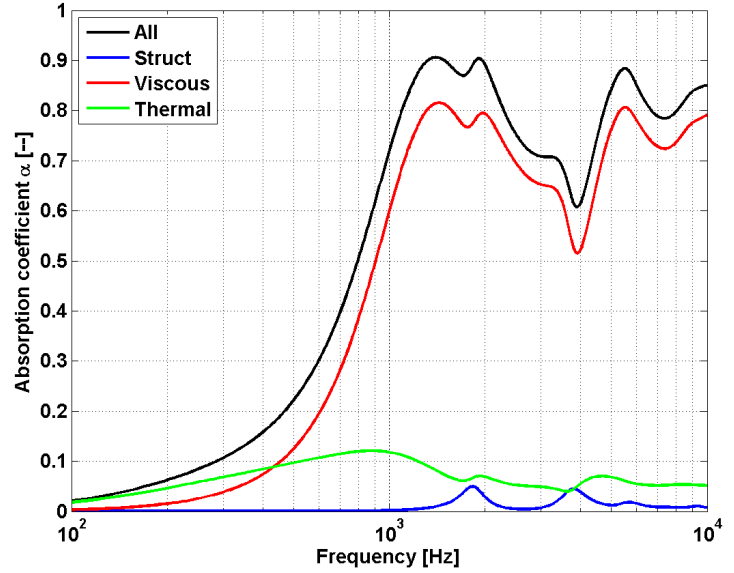

(a) Normalized by incident energy

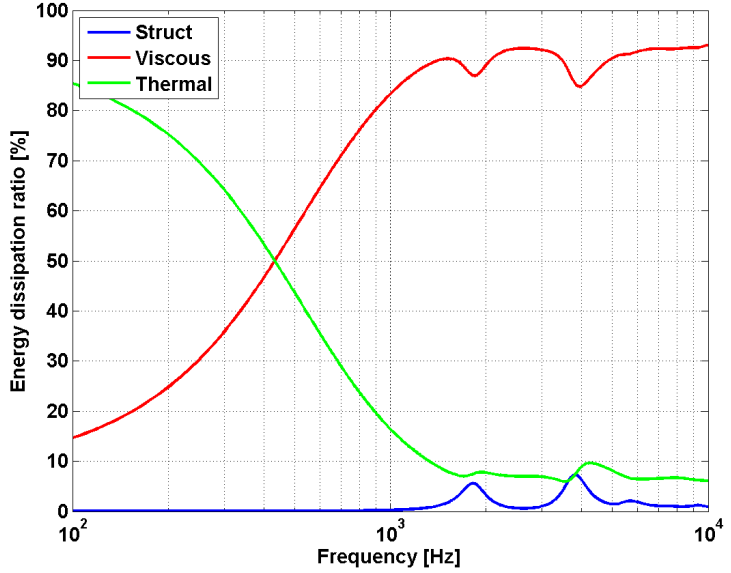

(b) Normalized by total dissipated energy

Fig. 7 Dissipated energy in polyurethane foam. Left figure shows dissipated energies normalized by incident energy. Right figure shows dissipated energies normalized by total dissipated energy. Blue represents energy dissipated by structural damping, red by viscosity of air, green by thermal conduction. Black shows total dissipated energy. Acoustic energy is mainly dissipated by thermal conduction in low frequency range below $300 \mathrm{~Hz}$, and by viscous damping in high frequency range above $1 \mathrm{kHz}$.

\section{6. まと め}

本研究では，垂直入射吸音率の場合に限定し，1 次元の音響管内を伝播する音波に対する波動方程式の理論解 を用い，固体相の構造減衰による散逸エネルギー，流体相の粘性減衰による散逸エネルギー，および流体相から 固体相への熱伝導による散逸エネルギーを陽に表した。繊維材料，圧縮した繊維材料およびポリウレタンフォー ムについて，散逸エネルギーの寄与を分析した結果，低周波では熱による散逸，高い周波数では粘性による散逸 が支配的であり，構造減衰による散逸は $10 \mathrm{kHz}$ までの周波数帯域では小さく，10\%以下であった。また，粘性に よる散逸エネルギーは，固体相に対する流体相の相対速度に関係しており，固体相の共振により振動速度が大き 
くなる周波数では相対速度が小さくなり粘性による散逸エネルギーが小さくなることを示した.

今後は, 著者が提案している微視構造モデルによるマルチスケール解析を用いて散冕エネルギーを微視的に求 め，多孔質材の微視構造設計につなげることを考えている.

\section{謝辞}

本研究の一部は JSPS 科研費 $17 \mathrm{~K} 06238$ の助成を受けたものです.

\section{References}

Allard, J. F. and Atalla, N., Propagation of Sound in Porous Media, Wiley (2009), pp.111-135.

Atalla, N., Panneton, R. and Debergue, P., A mixed displacement-pressure formulation for poroelastic materials, Journal of Acoustical Society of America, Vol. 104, No.3 (1998), pp.1444-1452.

Biot, M. A., Theory of propagation of elastic waves in a fluid-saturated porous solid. I. Low-frequency range, Journal of Acoustical Society of America, Vol. 28, No. 2 (1956a), pp.168-178.

Biot, M. A., Theory of propagation of elastic waves in a fluid-saturated porous solid. II. Higher frequency range, Journal of Acoustical Society of America, Vol. 28, No. 2 (1956b), pp.179-191.

Dazel, O., Brouard, B., Depoiller, C. and Griffiths, S., An alternative Biot's displacement formulation for porous materials, Journal of Acoustical Society of America, Vol. 121, No. 6 (2007), pp. 3509-3516.

Sgard, F. C., Atalla, N. and Nicolas, J., A numerical model for the low frequency diffuse field sound transmission loss of double-wall sound barriers with elastic porous linings, The Journal of the Acoustical Society of America, Vol. 108, No. 6 (2000), pp. 2865-2872.

Yamamoto, T., Maruyama, S., Terada, K., Izui, K. and Nishiwaki, S., A generalized macroscopic model for sound-absorbing poroelastic media using a homogenization method, Computer Methods in Applied Mechanics and Engineering, Vol. 200, No. 1 (2011), pp. 251-264. 